\title{
Decreased NK cell activity after partial vulvectomy in pregnant patient with vulvar intraepithelial neoplasia 3 (VIN3)
}

\author{
Malgorzata Jerzak' ${ }^{1}$ Andrzej Nowakowski' , Monika Kniotek² ${ }^{2}$ Andrzej Górski², \\ Włodzimierz Baranowski' \\ ${ }^{1}$ Department of Gynecology and Gynecological Oncology, Military Institute of Medicine, Warsaw, Poland
${ }^{2}$ Department of Clinical Immunology, Transplantation Institute, University Medical School, Warsaw, Poland
}

Jerzak M, Nowakowski A, Kniotek M, Górski A, Baranowski W. Decreased NK cell activity after partial vulvectomy in pregnant patient with vulvar intraepithelial neoplasia 3 (VIN3). Ann Agric Environ Med. 2017; 459-463. doi: 10.26444/aaem/72542

\begin{abstract}
Introduction and objective. The study presents the problem of immune disturbances in pregnant women with vulvar carcinoma in situ (VIN3).

Material and methods. NK cell and T reg activity in the study patient were analysed using flow cytometry.

Results. Decreased NK cell activity and but increased T reg activity were observed after vulvectomy, with subsequent successful pregnancy outcome.

Conclusions. Although vulvar cancer may influence immune cell activity, this issue merits further study.
\end{abstract}

\section{Key words}

vulvar cancer, NK cell, pregnancy, T reg

\section{INTRODUCTION}

Vulvar cancer is the fourth most common gynecological cancer and comprises 5\% of all malignancies of the female genital tract [1]. Two distinct types of vulvar intraepithelial neoplasia (VIN) with different pathogenesis, molecular events, morphological features and risk of progression to squamous carcinoma are determined [2]. A more common 'usual type of VIN' (also referred to as classic, undifferentiated, basaloid, warty, bowenoid type) is related to infection with Human Papillomavirus (HPV) which has a low risk of progression to invasive carcinoma. However, the chances of finding invasive cancer within the lesion of a usual type VIN cannot be excluded. A rarer, 'differentiated' (simplex) non-HPV-related VIN type is sometimes associated with lichen sclerosus, and it has a high risk of progression to invasive lesions. Incidence of the usual type VIN and HPVrelated invasive vulvar cancer has been increasing, especially in younger women $[3,4-6]$.

Genital infection with HPV is usually transient since the immune system is able to eliminate the virus. However, VIN may develop during persistent viral infection in the case of immune system failure. The natural history of VIN development and progression/regression is not fully elucidated, especially in pregnancy [7]. Pregnancy may contribute to spontaneous regression of VIN3, but the recurrence of VIN 3 twelve weeks after resection of vulvar cancer during pregnancy has been described [8].

Some data suggest that inflammatory activation in the dermis is reflected by the influx of NK cells and T cells as a response on viral HPV infection in VIN patients [9]. Studies describing the distribution of immunocompetent cells on VIN lesions are very limited [9]. The observed increase of NK cells in the dermis of the usual-type VIN lesions is in accordance with activation of the innate immune response. $\mathrm{CD} 4+\mathrm{CD} 25+\mathrm{T}$ regs cells play an important role in the mechanism of escape from immune surveillance in the process of tumour progression, and $\mathrm{T}$ regs suppress the tumour specific immune response [10]. The expression of factor forkhead boxP3 (FOXP3), a marker of T regs, was detected within vulvar cancer cell nests and in the tumor stroma. Recently, $\mathrm{T}$ regs were detected as a significantly higher population in the tumor compared with normal tissues [11].

Elevated numbers of peripheral blood NK cells and increased infiltration of endometrial NK cells have been reported as complications related to pregnancy, such as miscarriage $[12,13]$. Although immunophenotypes of the majority of peripheral blood NK cells are different from endometrial NK cells, the peripheral blood NK cells seem to be keenly related to decidual NK cells and may reflect the decidual NK cell functional status [12-14]. It is now also accepted that uterine NK cells are at least partially derived from blood [14]. Additionally, some data suggest that women with RM have altered peripheral blood NK parameters, and NK cells as a percentage of lymphocytes best discriminate $\mathrm{RM}$ and control women [15-17].

\section{OBJECTIVE}

The aim of the study was to determine peripheral blood NK cell and $\mathrm{T}$ reg activity after partial vulvectomy in pregnant women with VIN 3. According to current knowledge, there exist only very limited data regarding immune aspects during pregnancy complicated by VIN. 


\section{MATERIALS AND METHODS}

A 36-year-old pregnant woman, 16 weeks into her second pregnancy, second delivery, was studied. Gestational age was assigned on the last menstrual period and ultrasound examination. Consent for the study was obtained from the Bioethics Committee of the Military Institute of Medicine and from the patient. The patient was $\operatorname{HPV}$ - DNA $(6,11,16,18$, $31,33,35,39,45,51,52,56,58,59)$ negative (cervical smear). Colposkopy was satisfactory with no abnormalities observed. According to vulvar biopsy performed with vulvoscopy at 16 weeks of gestation and histologic diagnosis: dysplasia maioris gradus et partim carcinomatosa intraepidermale (in situ) epithelii superficialis vulvae (VIN 3; CIS) the patient underwent partial vulvectomy-surgical excision at 22 weeks of gestation because of increased spread of vulvar changes. Final histologic results were as follow: carcinoma intraepidermale Bowenoidale (in situ) with free surgical margins $1-2 \mathrm{~mm}$. Subsequentl pregnancy outcome was uncomplicated. However, routine high-risk obstetrics care, including periodic uterine ultrasonography and foetal heart monitoring, was provided. A normal, healthy boy of 2,720 $\mathrm{g}$ was delivered by caesarean section at 37 weeks of gestation. Two weeks after delivery, simple hemivulvectomy was performed because of clinically suspected changes of the vulvae and narrow free surgical margins after the previous operation, according to patient request. However, histologic examination of the removed vulvar tissue revealed no abnormalities.

Flow Cytometry analysis of NK cells. Natural killer cell activity was measured using flow cytometry. The NK cells' methodology has been described previously [17]. The peripheral blood NK cells' surface antigens CD16, CD56 were also studied using flow cytometry (Simultest CD3/ CD16+CD56, FACSCalibur, Cell Quest software, BectonDickinson).

NK assay - Separations of effector cells. Peripheral blood mononuclear cells (PBMC) were isolated from heparinized blood of the patient by Ficoll gradient centrifugation. The mononuclear cells are adjusted to $1 \times 10^{7}$ cells $/ 2.6 \mathrm{ml}$ in culture medium (RPMI 1640, 10\% FBS). Target cells were human erythroleukemia K562 (ATTC, UK). The K562 human erythroleukemia cell line is used as a standard target for human NK assays. K562 cells were washed in PBS $120 \mathrm{~g}$ and labeled with 1.2ml DIO (3,3-dioctadecyloxacarbocyxacarbocyanine perchlorate, (Sigma) $/ 1 \mathrm{ml}$ PBS and incubated for $20 \mathrm{~min}$ in $37^{\circ} \mathrm{C} \mathrm{CO}_{2}$. After two washes in PBS, cell concentration was adjusted to $1 \times 10^{6}$ cells/ml in medium (RPMI 1640, 10\% FBS) and used for cytotoxity assay.

Cytotoxity assay. Groups of eight replicate wells were incubated for $4 \mathrm{~h}$ in $37^{\circ} \mathrm{C} 5 \% \mathrm{CO}_{2}$ : PBMC in medium, $\mathrm{K} 562$ in medium, mixed PBMC with target cells in ratios: 50:1 and $12: 1.25 \mathrm{ml}$ propidium iodide solution $(0.1 \mathrm{mg} / \mathrm{ml}$ in water, Sigma) was added to each sample to stain dead cells (total volume in each sample $0.2 \mathrm{ml}$ ). Live target cells (T) were identified by strong green fluorescence, whereas dead target cells (Td) showed strong green and red fluorescence. The percentage of dead target cells (\%Td) was calculated as follows: $\% \mathrm{Td}=(\mathrm{Td} / \mathrm{T}) \times 100 \%$. Specific lysis was calculated as \%Td (cultured with effector cells - \%Td (cultured without effector cells).
Flow Cytometry analysis of T reg cells. For identification and evaluation of T reg cells, MNCs were stained with anti-CD4 (PerCP) and anti-CD25 (APC) monoclonal antibodies (all from BD Biosciences, San Jose, USA), as described previously (Baecher-Allan et al., 2001; Bocian et al., 2009). This was followed by intracellular staining of FOXP3 using the FITC Anti-Human Foxp3 Staining Set (eBioscience Inc., San Diego, USA) according to the manufacturer's instructions. IgG1 conjugated with the respective fluorochromes served as isotype control.

Flow cytometry analysis was carried out on a FACSCalibur using Cell Quest software (BD Biosciences, San Jose, USA). The cells were specifically analysed by selective gating. The results were based on analysis of at least 100,000 cells and were shown as the percentage of positively labelled cells.

HPV Genotyping. Cytological material from the uterine cervix was collected with a brush, suspended in Sure Path ${ }^{\mathrm{TM}}$ solution and formalin-fixed, paraffin-embedded vulvar biopsy specimen sectioned on a microtome, deparaffinized and rehydrated, were tested for the presence and type of HPV by real time PCR in a Nucleagena Laboratory in Poland. The tests used enabled detection of Low Risk HPV types: 6 and 11, and High Risk HPV types: 16, 18, 31, 33, 35, 39, 45, 51, 52, 56, 58,59 . Cytological material from the cervix was HPV negative but the vulvar biopsy specimen was positive for HPV 16.

\section{RESULTS}

Flow cytometry analysis revealed a decrease in the number of NK cells and their activity after the operation on the study woman (Tab. 1; Fig. 1). In addition, the T reg population was decreased; however, their activity increased after the operation (Figs. 2, 7).

Table 1. T cell and NK cell markers expressions (percentage) before and after operation

\begin{tabular}{lccccccc}
\hline & $\begin{array}{c}\mathrm{CD} 3 \\
(\%)\end{array}$ & $\begin{array}{c}\mathrm{CD} 4 \\
(\%)\end{array}$ & $\begin{array}{c}\mathrm{CD} 8 \\
(\%)\end{array}$ & $\begin{array}{c}\mathrm{CD} 5 / \mathrm{CD} 19 \\
(\%)\end{array}$ & $\begin{array}{c}\mathrm{CD} 16 \\
(\%)\end{array}$ & $\begin{array}{c}\text { CD56 } \\
(\%)\end{array}$ & $\begin{array}{c}\text { NK activity } \\
\text { of cell (\%) }\end{array}$ \\
\hline Before vulvectomy & 73 & $\mathbf{4 4}$ & 30 & 13 & $\mathbf{1 4}$ & $\mathbf{1 1}$ & $\mathbf{3 1}$ \\
\hline After vulvectomy & 80 & $\mathbf{5 2}$ & 27 & 10 & $\mathbf{5}$ & $\mathbf{6}$ & $\mathbf{1 0}$ \\
\hline
\end{tabular}

\section{DISCUSSION}

Regression of VIN can occur in young women before their thirties, especially during pregnancy. However, the chances of finding invasive cancer within the lesions of the usual type VIN range between 15 - 22\% [18-20]. Therefore, the decision to perform vulvectomy because of the progression of the lesion was made very rapidly.

Some data suggest that expression of CD4+CD25+ T reg correlates with persistence of HPV type 16. T regs may inhibit the HPV clearance by immune cells, such as NK cells [21]. Recent data of Kojima et al. demonstrate that CD4+CD25+ Foxp3 $+\mathrm{T}$ regs infiltration into cervical intraepithelial neoplasia (CIN) lesions, a lesion similar to VIN, significantly correlates with regression of CIN, regardless of the HPV subtype. Conversely, a high prevalence of lesional cervical Tregs may be a biomarker for HPV infection persistence and CIN progression [22]. Similar mechanism may also be involved in VIN progression. 


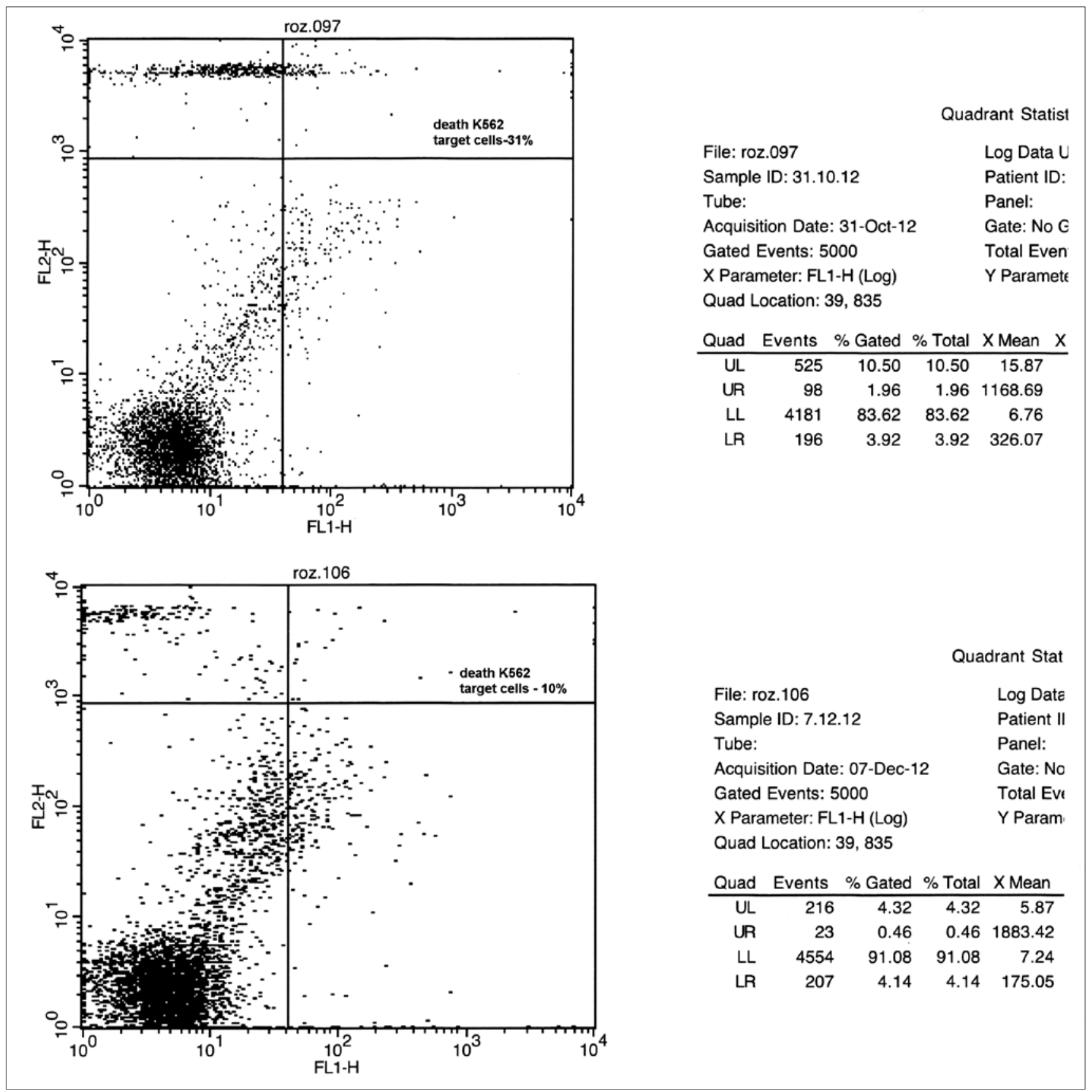

Figure 1. Flow cytometry analysis of NK-cell activity before (upper part of the Figure) and after (lower part of the Figure)

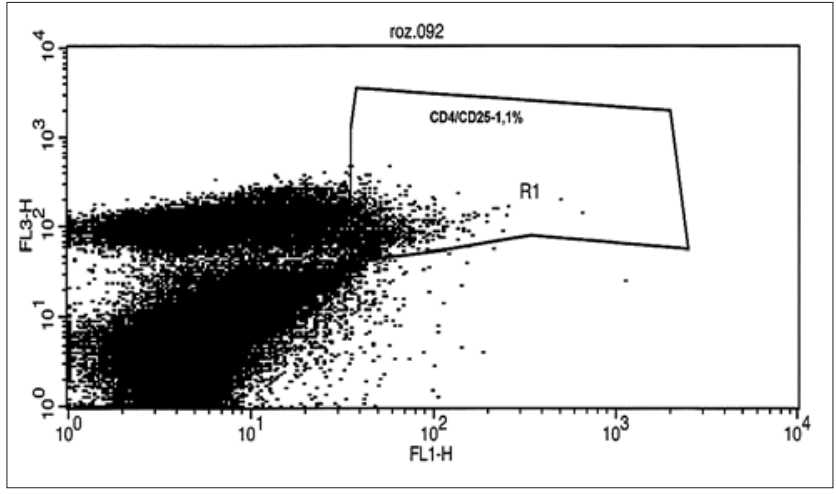

Figure 2. $C D 4+C D 25+($ T reg) before operation

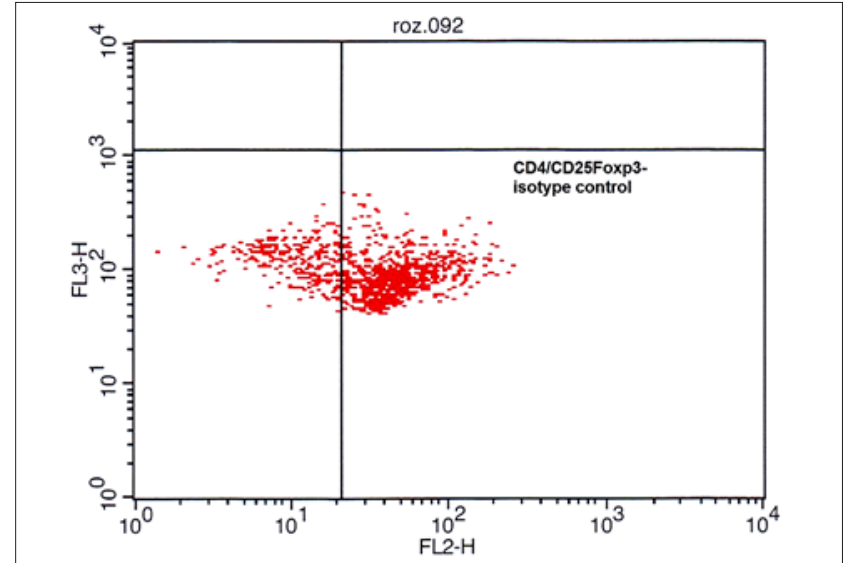

Figure 3. $C D 4+C D 25+$ Foxp3- isotype control before operation 


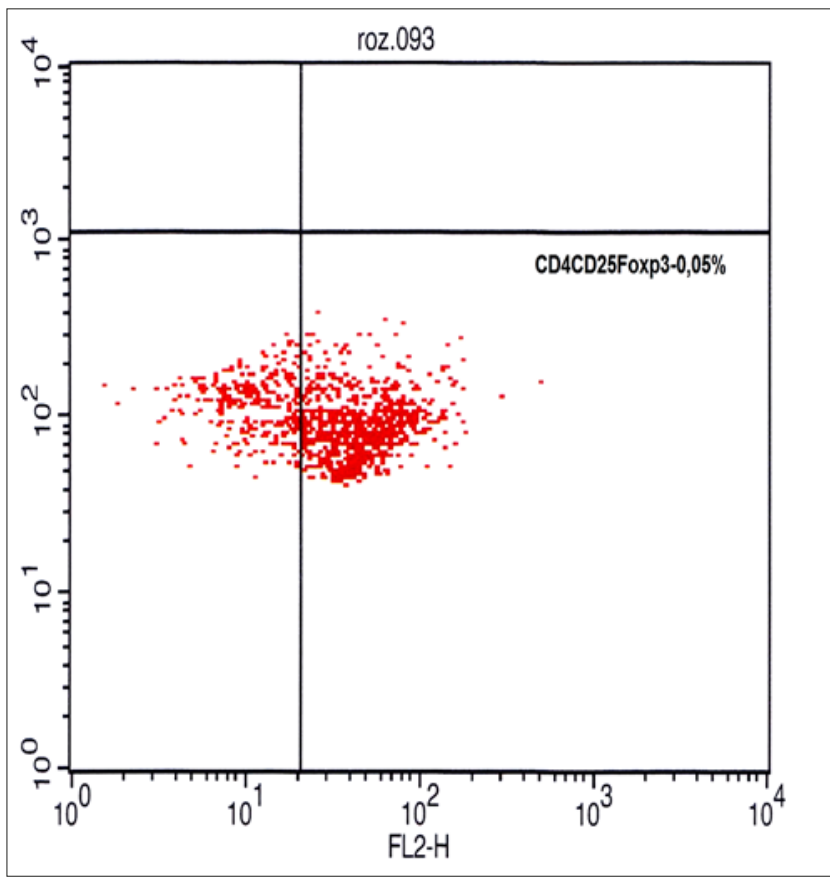

Figure 4. $C D 4+C D 25+$ Foxp3+ cells before operation

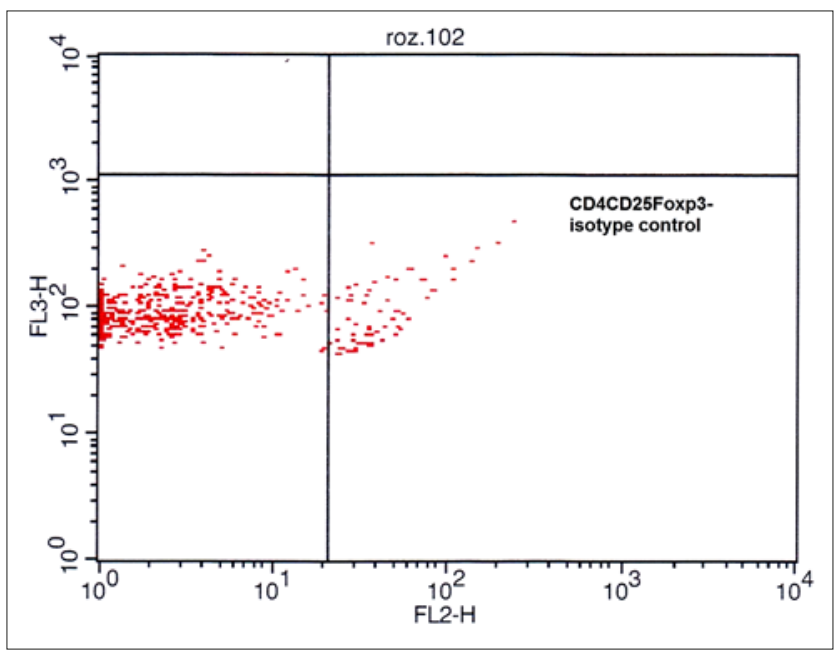

Figure 6. CD4+CD25+ Foxp3 - isotype control after operation

\section{CONCLUSIONS}

In the study case, vulvectomy changed the immune parameters. It cannot be excluded the that operation was necessary for a successful pregnancy outcome, because increased NK cell parameters are associated with adverse pregnancy outcomes, including miscarriage. However, this issue merits further study which, however, is very difficult to perform since pregnant patients with VIN are rather rare in the clinical setting, and no generally accepted standards and recommendation of managements exist.

\section{REFERENCES}

1. Siegel R, Ward E, Brawley O, Jemal A. Cancer statistics, 2011: the impact of eliminating socioeconomic and racial disparities on preamature cancer death. CA Cancer J Clin 2011; 61:212-36

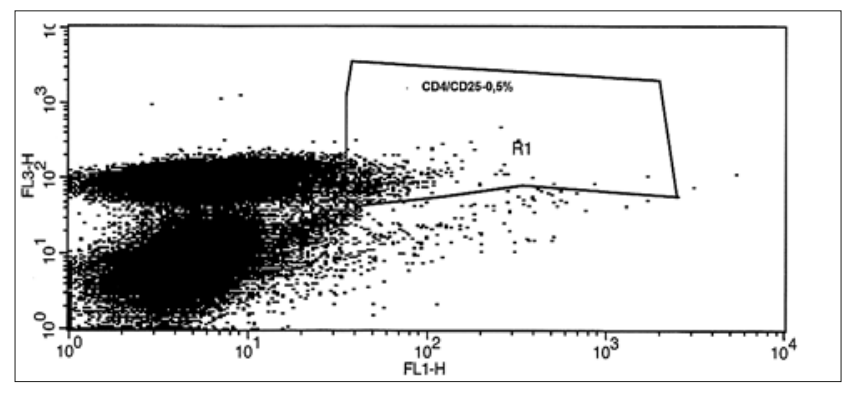

Figure 5. $C D 4+C D 25+(T$ reg) after operation

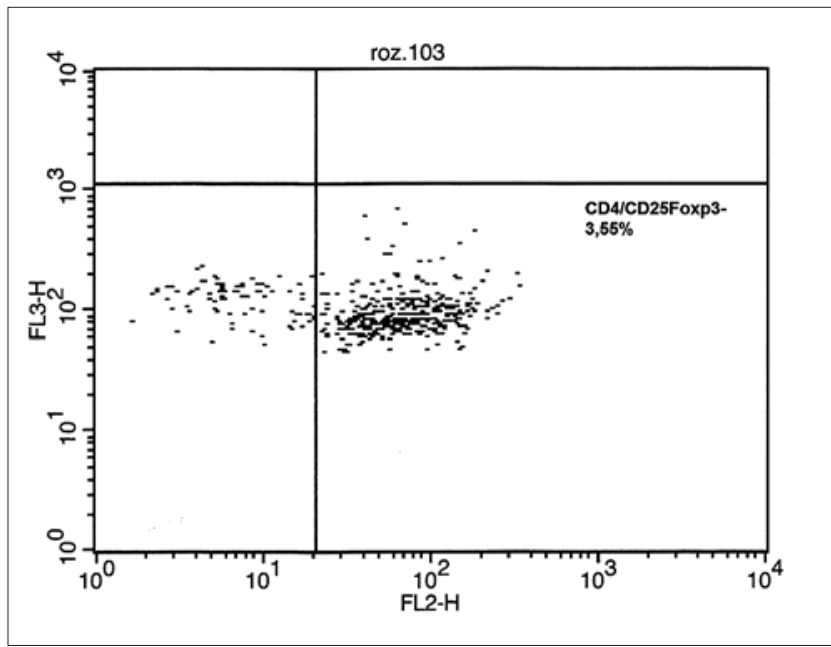

Figure 7. $C D 4+C D 25+$ Foxp3+ cells after operation

2. McCluggage WG. Premalignant lesions of the lower female genital tract: cervix, vagina and vulva. Pathology 2013; 45: 214-28.

3. Jones RW, Baranyai J, Stables S. Trends in squamous cell carcinoma of the vulva: the influence of vulvar intraepithelial neoplasia. Obstet Gynecol. 1997; 90: 448-52.

4. Joura EA, Lösch A, Haider-Angeler MG, Breitenecker G, Leodolter S. Trends in vulvar neoplasia. Increasing incidence of vulvar intraepithelial neoplasia and squamous cell carcinoma of the vulva in young women. J Reprod Med. 2000; 45: 613-5.

5. Judson PL, Habermann EB, Baxter NN, Durham SB, Virnig BA. Trends in the incidence of invasive and in situ vulvar carcinoma. Obstet Gynecol. 2006; 107: 1018-22.

6. Baandrup L, Varbo A, Munk C, Johansen C, Frisch M, Kjaer SK. In situ andinvasive squamous cell carcinoma of the vulva in Denmark 1978-2007 - a nationwide population-based study. Gynecol Oncol. 2011; 122: 45-9.

7. van Seters M, van Beurden M, de Craen AJ. Is the assumed natural history of vulvar intraepithelial neoplasia III based on enough evidence? A systematic review of 3322 published patients. Gynecol Oncol. 2005; 97: 645-51.

8. Ogunleye D, Lewin SN, Huettner P, Herzog TJ. Recurrent vulvar carcinoma in pregnancy. Gynecol Oncol. 2004; 95: 400-1.

9. Van Seters M, Beckmann I, Heijmans-Antonissen C, van Beurden M, Rwing PC, Zijlstra FJ, Helmerhorst TJM, KlrinJan A. Disturbed Patterns of Immunocompetent Cells in Usual-Type Vulvar Intraepithelial Neoplasia. Cancer Res. 2008; 68: 6617-6622.

10. Robbins SH, Bessoi G, Cornillon A, Zucchini N, Rupp B, Ruzsics Z, Sacher T, Tomasello E, Vivier E, Koszinowski UH, Dalod M.Natural killer cells promote early CD8 T cell responses against cytomegalovirus. PLoS Pathog. 2007; 3: 1152-64.

11. Sznurkowski JJ, Żawrocki A, Emerich J, Sznurkowska K, Biernat W. Expression of indoleamine 2,3-dioxygenase predicts shorter survival in patients with vulvar squamous cell carcinoma (vSCC) not influencing on the recruitmrnt of FOXP3-expressing regulatory $\mathrm{T}$ cells in cancer nests. Gynecol Oncol. 2011; 122: 307-312.

12. Ntrivalas EI, Kwak-Kim JY, Gilman-Sachs A, Chung-Bang H, Ng SC, Beaman KD, et al. Status of peripheral blood natural killer cells in women with recurrent spontaneous abortions and infertility of unknown aetiology. Hum Reprod. 2001; 16: 855-861. 
13. Aoki K, Kajiura S, Matsumoto Y, OgasawaraM, Okada M, Yagami Y, et al. Preconceptional natural- killer- cell activity as a predictor of miscarriage. Lancet 1995; 345: 1340-1342.

14. Santoni A, Carlino C, Stabile H, Gismondi A. Mechanisms underlying recruitment and accumulation of decidual NK cells in uterus during pregnancy. Am J Reprod Immunol. 2008; 59: 417-424.

15. Yamada H, Morikawa M, Kato EH, Shimada S, Kobashi G, Minakami H. Pre-conceptional natural killer cell activity and percentage as predictors of biochemical pregnancy and spontaneous abortion with normal chromosome karyotype. Am J Reprod Immunol. 2003; 50: 351-4.

16. King K, Smith S, Chapman M, Sacks G. Detailed analysis of peripheral blood natural killer (NK) cells in women with recurrent miscarriage. Hum Reprod. 2010; 25: 52-58.

17. Jerzak M, Kniotek M, Mrozek J, Górski A, Baranowski W. Sildenafil citrate decreased NK cell activity and enhanced chance of successful pregnancy in women with a history of recurrent miscarriage. Fertil Steril. 2008; 90: 1848-1853.

18. Jones RW, Rowan DM. Spontaneous regression of vulvar intraepithelial neoplasia 2-3. Obstet Gynecol. 2000; 96: 470-472.
19. Jones RW, Rowan DM, Stewart AW. Vulvar intraepithelial neoplasia: aspects of natural history and outcome in 405 women. Obstet Gynecol. 2005; 106: 1319-26.

20. Maclean AB. Vulval cancer: prevention and screening. Best Pract Res Clin Obstet Gynaecol. 2006; 20: 379-95.

21. Molling JW, de Gruijl TD, Glim J, Moreno M, Rozendaal L, Meijer CJ, van den Eartwegh AJ, Scheper RJ, von Blomberg ME, Bontkes HJ. CD4(+)CD25hi regulatory $\mathrm{T}$-cell frequency correlates with persistence of human papillomavirus type 16 and $\mathrm{T}$ helper cell responses in patients with cervical intraepithelial neoplasia. Int J Cancer 2007; 121: 1749-1755.

22. Kojima S, Kawana K, Tomio K, Yamashita A, Taguchi A, Miura S, Adachi K, Nagamatsu T, Nagasaka K, Matsumoto Y, Arimoto T, Oda K, Wada-Hiraike O, Yano T, Taketani Y, Fujii T, Schust DJ, Kozuma S. The prevalence of cervical regulatory $\mathrm{T}$ cells in HPV-related cervical intraepithelial neoplasia (CIN) correlates inversely with spontaneous regression of CIN. Am J Reprod Immunol. 2013; 69: 134-141. 